\title{
Preferences of people with disabilities on wheelchairs in relation to forest trails for recreational in selected European countries
}

\author{
Emilia Janeczko ${ }^{1}$, Mariana Jakubisová ${ }^{2}$,Małgorzata Woźnicka1 , Jitka Fialova³, \\ Pavla Kotásková ${ }^{3}$ \\ ${ }^{1}$ Warsaw University of Life Sciences, Faculty of Forestry, Department of Forest Utilization, Nowoursynowska 159 , \\ 02-776 Warsaw, Poland, phone: +48 22 5938134, e-mail: emlia.janeczko@wl.sggw.pl \\ 2 Technical University in Zvolen, The Borová hora Arboretum, Borovianska cesta 2171/66, 96053 Zvolen, Slovak Republic \\ ${ }^{3}$ Mendel University in Brno, Faculty of Forestry and Wood Technology, Department of Landscape Management, \\ Zemedelska 3, 61300 Brno, Czech Republic
}

\section{Abstract}

The article presents the results of the survey on the preferences of disabled people in wheelchairs for selected features recreational trails in the woods. The study was conducted in 2015, including a sample of 130 people older than 18 years, in Poland, the Czech Republic and Slovakia (52 interviews in Poland, 21 in the Czech Republic and 57 in Slovakia). Respondents were interviewed both at the premises of the organisation as well as by email. The questions in the survey were designed to determine the preferences of the respondents in terms of recreational trails in the forests concerned: the optimal length of the route, recreational and educational points along the distribution routes of and usability of different types of forest roads. The results show that there is quite a lot of differences between the preferences of respondents from each of the analysed countries. Respondents from the Poland and Slovakia prefer shorter routes for recreation in forests, with a greater incidence of recreational and educational points along the route, whilst respondents in the Czech Republic prefer far longer routes, with a relatively larger distance between recreational points. In all the analysed countries, people with disabilities attributed highest usefulness to asphalt surfaces, concrete surfaces or surfaces made of cobblestones. The surface evaluated lowest for usability was made of wood.

\section{KEY WORDS}

disabled, development of tourism, recreation management, forest recreation management, forest roads

\section{INTRODUCTION}

Forests, in both Poland and many other countries, including the Czech Republic and Slovakia, because of the space it occupies $(29.2 \%, 34 \%$ and $40 \%$, respec- tively) as well as the spatial distribution, are seen as one of the fundamental values of the recreation. Proper management of recreational forest requires consideration of social needs and expectations whilst caring about the natural environment and landscape. In 
recent years, Poland and neighbouring countries are turning more and more attention to the adaptation of tourism infrastructure, recreation and education also for people with disabilities (Woźnicka 2007; Loučková and Fialová 2010; Jakubis and Jakubisová 2010). Currently, persons with disabilities constitute about $12 \%$ of Polish society (CSO 2014), 10\% of the population of the Czech Republic (Czech Statistical Office 2014) and $8 \%$ of the population of the Slovak (Slovakia Statistical Office 2014). Tourism and recreation in forest areas play a very important role in the lives of people with disabilities. Tourism for people with disabilities should be treated according to Łobożewicz (2000) not only as entertainment and for relaxation but also as a means of therapy and education for and calming effects on the disability, allowing them to try their hand at different often difficult conditions. According to many experts on the issues of rehabilitation of persons with disabilities (Łobożewicz 2000; Wolski 1979; Weiss 1979; Jakubisová 2013) cultivation of tourism can counteract hypokinesis as well as accelerate and support the processes of renewal and regeneration of the body. Tourism also allows people with disabilities to socially integrate and adapt to normal life (Junek and Fialova 2012). The majority of tourist activities undertaken by humans takes place in the natural environment (Navratil et al. 2015). Forest gives people the opportunity to realise various forms of tourism and recreation. In all activities of tourism, recreation, leisure and education in the forests, they may participate as people with disabilities, regardless of the type of disability, age and psycho-motor possibilities. According to Łobożewicz (2000), practice shows that there is no discipline in tourism that could not be occupying for people with disabilities. The possibility of recreational use of the forest by people with disabilities is mainly conditioned by the availability of hiking trails and recreational trails including walking paths and educational paths. Linear features enable full use of the advantages of the forest environment and allow to reach interesting places in terms of natural and cultural heritage. The desired aim of this article is to determine the preferences of people with disabilities in wheelchairs, who are the inhabitants of Polish, the Czech Republic and Slovakia, in respect of the selected features of forest recreational trails, such as the optimal length of the route, recreational and educational points along the distribution routes and usability of different types of forest roads.

\section{Material AND MEthods}

The article presents the results of surveys conducted in 2015 on a group of people with disabilities in wheelchairs. The research was conducted within the framework of the programme funded by the Visegrad Foundation simultaneously in Poland, the Czech Republic and Slovakia. The respondents were people with disabilities in wheelchairs assigned in activating associations (e.g. in Poland: Foundation for Active Rehabilitation; in the Czech Republic: League of Wheelchair Users; in Slovakia: the National Rehabilitation Centre in Kovacova, the Slovak Association of the Disabled, the Slovak Physical Disability Association, the Slovakian Paraolimpic Committee). The form of the questionnaire for respondents, the system of questions and cafeterias located in the closed questions were consulted with experienced workers and sociologists rehabilitation centres for disabled. The study was conducted jointly on trial with 130 people older than 18 years (52 interviews in Poland, 21 in the Czech Republic and 57 in Slovakia). The questionnaire was carried out either at the premises of the above organisations or by email. The questionnaire was created and published on Google pages. Information on how to complete the questionnaire directly online via the Internet was communicated on the Facebook page. The resulting research material was verified and coded. The collected material was stored in the form of a computerised database, created in Excel, on the basis of which the result tables were built.

For statistical analysis, analysis of variance was used at a significance level of 0.05 , and the comparisons were performed using post-hoc Duncan test. Statistical analysis was performed to determine the statistically significant differences between the preferences of people with disabilities living in Poland, the Czech Republic and Slovakia. The questions in the survey were designed to determine the preferences of the respondents in terms of selected features in recreational trails in the forests concerned, such as the optimal length of the route; recreational facilities along the distribution routes, for example, holiday sites, picnic areas, educational points; and usability of different types of forest roads. 


\section{Results}

The results of research conducted in Poland show that according to the survey, the majority (about 71.2\%) indicated that the length of trails in the forest should not exceed $4 \mathrm{~km}$. The length should be $2-4 \mathrm{~km}$ for $32.7 \%$ of respondents and $1-2 \mathrm{~km}$ for $30.8 \%$ of respondent. According to $7.7 \%$ of respondents, trail length should not exceed $1 \mathrm{~km}$, whilst $23 \%$ of respondents could not determine the preferred length of the trail. About 5.8\% of respondents indicated that the trail length should be more than $4 \mathrm{~km}$. Most of the respondents (47.6\%) from the Czech Republic believed that forest trails and recreation facilities should be longer than $4 \mathrm{~km}$. More than $33.3 \%$ of them preferred the route with $2-4 \mathrm{~km}$ in length, $14 \%$ preferred the route with $1-2 \mathrm{~km}$ in length and $4.8 \%$ of respondents could not specify their preferred length of the trails for recreation. On the other hand, the dominant view of people living in Slovakia (a total of $61.4 \%$ of responses), as in Poland, is that the route for recreational trails should be up to $4 \mathrm{~km}$ in length. The majority of respondents $(38.6 \%)$ preferred route with a length of $2-4 \mathrm{~km}, 8.8 \%$ of the respondents preferred the very short route $(1 \mathrm{~km})$, nearly $14 \%$ of respondents were in favour of routes with a length of 1-2 km, whilst $19.3 \%$ of the respondents living in Slovakia preferred the long route (more than $4 \mathrm{~km}$ ). Just as in studies conducted in Poland, here also we can see that about $19 \%$ of the respondents could not specify their preferred long recreational trails. The analysis of variance confirmed that the views of the respond-

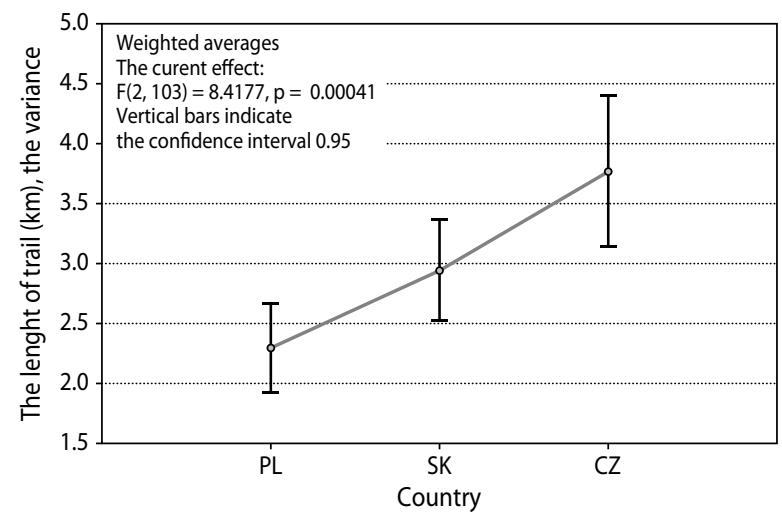

Figure 1. Comparison of the preferences of Polish respondents, Slovakia and the Czech Republic in terms of length of trails for recreation ( $95 \%$ trust intervals for the average) ent from the three analysed countries differ from each other $(p=0.0004)$ (Fig. 1).

An in-depth analysis using multiple comparison test (Duncan's test) showed that the opinions of Polish and Slovakian respondents about the optimal length of the route do not differ from each other. It was found here that there are basically significant differences in views between respondents from Poland and the Czech Republic and Slovakia (Tab. 1).

Table 1. Duncan test of variables - length of trail $(\mathrm{km})$

\begin{tabular}{|c|c|c|c|c|}
\hline \multirow[t]{2}{*}{ No. } & \multicolumn{4}{|c|}{$\begin{array}{c}\text { Duncan test; variables }- \text { length of trail }(\mathrm{km}) \\
\text { The approximate probability for post-hoc test } \\
\text { Error: ASS }=1,7597, \mathrm{DF}=103\end{array}$} \\
\hline & country & PL & SK & $\mathrm{CZ}$ \\
\hline 1 & PL & - & 0.058 & 0.000 \\
\hline 2 & SK & 0.058 & - & 0.016 \\
\hline 3 & $\mathrm{CZ}$ & 0.000 & 0.016 & - \\
\hline
\end{tabular}

According to most of the respondent from Poland (34.6\%), the distance between successive points along the recreational or educational paths should be at $200-500 \mathrm{~m}$. Quite large in this case, the group of respondents (30.8\%) believe that this distance should be 100-200 meters or more than half a kilometre (26.9\% of respondents). Only $7.7 \%$ of Polish respondents thought that educational spots and resting places should be located from each other at a distance of no more than $100 \mathrm{~m}$. The results of research conducted in Slovakia have shown, as in the case of research carried out in Poland, that the vast majority of respondents $(42.1 \%)$ is convinced of the need for the deployment of recreational facilities along the routes in the distance of $200-500 \mathrm{~m}$. At the same time, approximately $8.7 \%$ of the respondents were of the opinion that the holiday and education spots should be at $100-200 \mathrm{~m}$. Some of respondents $(24,6 \%)$ indicated smaller distance $(<100 \mathrm{~m})$ and longer then $500 \mathrm{~m}$. On the other hand, amongst those surveyed in the Czech Republic prevailed (52.4\% of respondents) the need for placing the devices along the trails for recreational holidays in the woods at a distance of not less than $500 \mathrm{~m}$ from each other. Quite numerous here was a group of respondents (33.3\%) declaring the need to introduce recreational facilities at $200-500 \mathrm{~m}$. About $14.3 \%$ of respondents were in favour of installing leisure time facilities at 100-200 $\mathrm{m}$ along the forest trails for recreational needs. However, there were 
not any respondents who prefer more frequent placement points, recreational and educational leisure routes and hiking trails that can pass through forests.

From the graphical analysis of variance it can be concluded that the respondents' views from three analyzed countries differ from each other $(p=0.023)$ (Fig. 2).

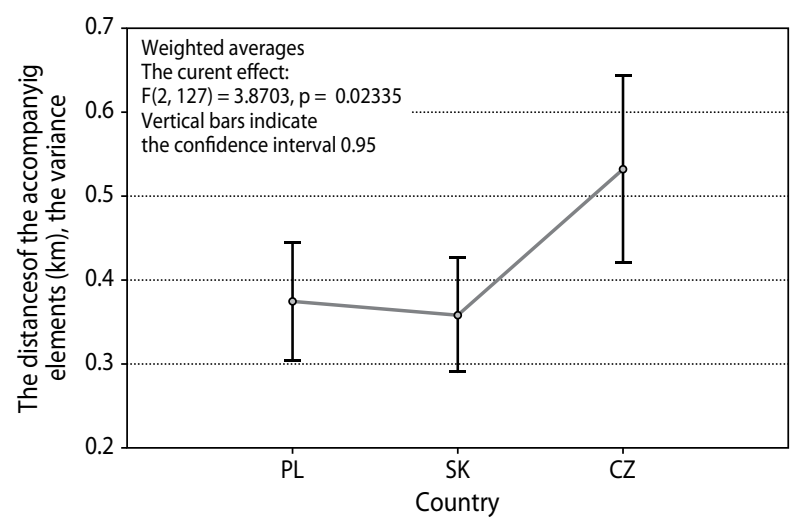

Figure 2. Comparison of the preferences of Polish respondents, Slovakian and from the Czech Republic considering (95\% trust intervals for the average) the distance between successive recreational and educational points along the forest trails for recreational purposes

Analysis of post-hoc Duncan test showed no statistically significant differences between the views of respondents of Poland and Slovakia on above-mentioned issues. Significantly different are the preferences within the three countries on the frequency of distribution of leisure time facilities and education facilities along forest trails for recreational needs (Tab. 2).

Table 2. Duncan test of variables - the preferred distance of holiday destinations along the recreational trails

\begin{tabular}{|c|c|c|c|c|}
\hline \multirow{2}{*}{ No. } & \multicolumn{4}{|c|}{$\begin{array}{r}\text { Duncan test; variables - the preferred distance } \\
\text { holiday destinations along the recreational trails } \\
\text { The approximate probability for post-hoc test } \\
\text { Error: ASS }=0,064, \mathrm{DF}=127\end{array}$} \\
\cline { 2 - 5 } & country & PL & SK & CZ \\
\hline 1 & PL & - & 0.789 & 0.008 \\
\hline 2 & SK & 0.789 & - & 0.005 \\
\hline 3 & CZ & 0.008 & 0.005 & - \\
\hline
\end{tabular}

Another analysed characteristics of the recreational trails was the surface. The types of surfaces such as natural, hardened gravel, asphalt, made from wood (wooden bridge), paving and pavement with concrete slabs were evaluated in terms of usability for people with disabilities in wheelchairs using a four-point scale (unnecessary, rarely needed, rather necessary, required). Research conducted in Poland showed that surfaces such as concrete slabs, asphalt and paving stones were considered to be most suitable for people in wheelchairs (high percentage of respondents $(90.4 \%, 96.2 \%$ and $59.6 \%$, respectively) recognised the surface as easy and very easy to use). In Slovakia and the Czech Republic, the vast majority of respondents also pointed to the great usefulness of asphalt $(94.7 \%$ and $90.9 \%$, respectively). The views of respondents in the Czech Republic and Slovakia on the high usefulness of the surface of the concrete slabs and paving cobblestone were not as strong as those in the case of Polish respondents. The vast majority of respondents in the Czech Republic and Slovakia (36.4\% and $45.6 \%$, respectively) indicated that the surface of the concrete slab is moderately friendly for wheelchair users. In turn, the paving has been assessed by the majority of respondents from the Czech Republic (50\%) as a surface unsuitable for wheelchairs. The majority of Slovaks (43.9\%) considered this surface as moderately useful.

In Poland, the surface made of wood received the largest percentage of ratings $(5.8 \%)$ for 'useless surface'. This surface was considered unsuitable or less suitable by $46.2 \%$ of respondents from Poland. This type of surface was negatively rated by most of the respondents (57.2\%) from Slovakia, recognising it as unsuitable (14\% of respondents) or low usefulness (42.1\%). Similarly, a total of $50 \%$ of respondents in the Czech Republic indicated that the surface is not suitable for people in wheelchairs, including $22.7 \%$ of respondents indicated that the surface did not suit wheelchair users and $27.3 \%$ of the respondents were of the opinion that it is useful to a limited extent.

Amongst the large part of Slovak respondents $(77.2 \%)$, there is a view that the least friendly surface for people in wheelchairs is the ground paved with gravel $(42.1 \%$ considered this type of surface as not at all useful and $35.1 \%$ as too little useful for wheelchair users). Similarly, respondents from the Czech Republic (a total of $68.2 \%$ ) recognise this type of surface to be inadequate $(36.4 \%)$ or a little friendly $(31.8 \%)$ for persons in wheelchairs. At the same time, only $3.5 \%$ of the surveyed Slovaks and as much as $13.6 \%$ of the Czech 
respondents were of the opinion that it is a surface very friendly to people with disabilities in wheelchairs. In Poland, a total of $42.3 \%$ of the respondents recognised the hard surface gravel as unsuitable or less suitable for tourism of people with disabilities in wheelchairs.

Performed statistical analysis confirmed that only in the case of two types of surface, namely, asphalt and wood, there is no statistical difference between the preferences of people living in Poland, the Czech Republic and Slovakia. The views on usability of cobblestones are already fundamentally different from each other $(p=0.000)$, as shown by the analysis of variance (Fig. 3).

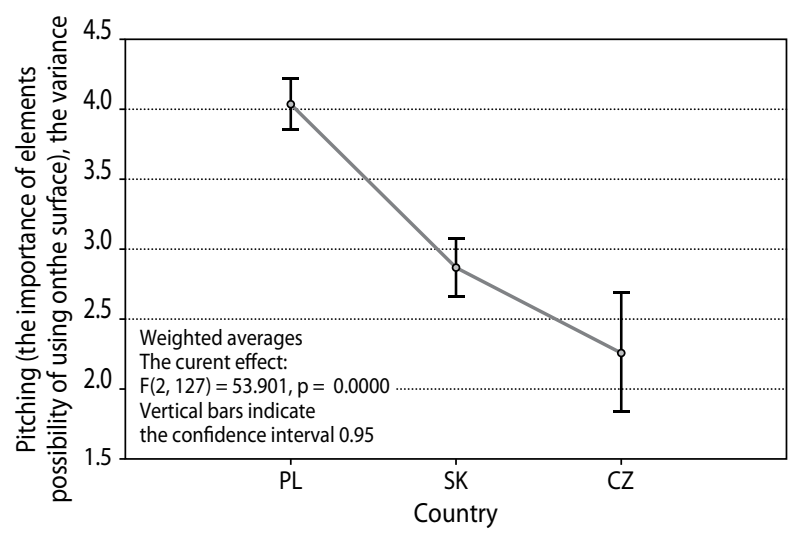

Figure 3. Comparison of the views of the respondents from the Poland, Slovakia and the Czech Republic on the suitability of the surface of the cobblestones $(95 \%$ confidence intervals for the mean)

An in-depth statistical analysis using multiple comparison test showed that there are differences between the preferences of the respondents living in Slovakia and the Czech Republic, Slovakia and Poland and the Czech Republic and Poland (Tab. 3).

Table 3. Duncan test of variables - type of pavement: cobblestone

\begin{tabular}{|c|c|c|c|c|}
\hline \multirow{3}{*}{ No. } & \multicolumn{4}{|c|}{$\begin{array}{r}\text { Duncan test; variables - type of pavement: } \\
\text { cobblestone }\end{array}$} \\
& \multicolumn{5}{|c|}{$\begin{array}{r}\text { The approximate probability for post-hoc test } \\
\text { Error: ASS }=0,568, \mathrm{DF}=127\end{array}$} \\
\cline { 2 - 5 } & country & PL & SK & CZ \\
\hline 1 & PL & - & 0.000 & 0.000 \\
\hline 2 & SK & 0.000 & - & 0.001 \\
\hline 3 & CZ & 0.000 & 0.001 & - \\
\hline
\end{tabular}

In the case of other variants of surface (natural, paved with gravel, concrete slabs), there were statistically significant differences in the preferences of the respondents coming from the Czech Republic and Slovakia (Tab. 4).

Table 4. Duncan test of variables - type of pavement: concise natural (A), paved with gravel (B) and concrete slabs (C)

\begin{tabular}{|c|c|c|c|c|}
\hline \multicolumn{5}{|c|}{ Duncan test; variables - type of pavement } \\
\hline & country & PL & SK & $\mathrm{CZ}$ \\
\hline \multirow[t]{2}{*}{ A } & \multicolumn{4}{|c|}{$\begin{array}{c}\text { Error: } \mathrm{ASS}=0.616, \mathrm{DF}=127 \\
\text { type of pavement: concise natural }\end{array}$} \\
\hline & country & PL & SK & $\mathrm{CZ}$ \\
\hline 1 & PL & - & 0.008 & 0.000 \\
\hline 2 & SK & 0.008 & - & 0.236 \\
\hline 3 & $\mathrm{CZ}$ & 0.000 & 0.236 & - \\
\hline B & \multicolumn{4}{|c|}{$\begin{array}{l}\text { Error: ASS }=0.720, \mathrm{DF}=127 \\
\text { type of pavement: paved with gravel }\end{array}$} \\
\hline 1 & PL & - & 0.000 & 0.007 \\
\hline 2 & SK & 0.000 & - & 0.209 \\
\hline 3 & $\mathrm{CZ}$ & 0.007 & 0.209 & - \\
\hline $\mathrm{C}$ & \multicolumn{4}{|c|}{$\begin{array}{l}\text { Error: } \mathrm{ASS}=0.475, \mathrm{DF}=127 \\
\text { type of pavement: concrete slabs }\end{array}$} \\
\hline 1 & PL & - & 0.000 & 0.000 \\
\hline 2 & SK & 0.000 & - & 0.963 \\
\hline 3 & $\mathrm{CZ}$ & 0.000 & 0.963 & - \\
\hline
\end{tabular}

\section{Discussion}

Studies were carried out on a relatively large sample that are not tested. This is due to at least two reasons, first, there is virtually no technical possibility to conduct the survey amongst people with disabilities in the woods. It is not usually difficult, because of the fact that forests are poorly adapted to the needs of people with disabilities, and besides, people with disabilities rarely visit forests. For example, the research by Woźnicka (2007) shows that $40 \%$ of the total length of roads in the forests of the city of Warsaw is available for people in wheelchairs. In large part, this is due to the poor technical condition of the surface of the road and too large vertical drops (Woźnicka 2009). Woźnicka (2006) by conducting a survey of persons with disabilities in the forests found that more than $40 \%$ of respondents rested 
in the woods just a few times a year. Therefore, a significant difficulty is getting to this part of the population. People with disabilities in wheelchairs do not form compact groups such as the blind or deaf. Often, for various reasons, they are also people alienated socially reluctant to seek information about their disability (Loučková and Fialová 2010).

So far in the literature in the field of tourism, development and recreation appeared different; the views on the optimal length of recreational trails are often contradictory. For example, according to Płocka (2002), walking in the woods should span a maximum length of $12 \mathrm{~km}$ optimally and be $8 \mathrm{~km}$ away. In turn, the optimal length of forest trails should be 1-2 km (Lonkiewicz and Głuch 1991). At the same time, there is a lack of information on the optimal length of routes for people with disabilities in wheelchairs, the needs and expectations of this social group. The study showed that in Polish conditions, as well as in the forests of Slovakia, recreational trail adapted for wheelchairs should not exceed $4 \mathrm{~km}$. According to a research conducted in the Czech Republic, it shows that these routes may be longer. Perhaps it has to do with the fact that in the Czech Republic prevailed $(50 \%)$ people moving in electric wheelchairs $(0 \%$ and $14 \%$ of respondents in Poland and Slovakia, respectively), much more comfortable and easy to use. Perhaps, therefore, it was the kind of wheelchair that affects the preferences of users. This view appears to be justified in the context of the results regarding the preferred spacing/distance between the successive recreational respectively. Most of the respondent from the Czech Republic preferred the spacing of recreational facilities at $500 \mathrm{~m}$, and more often, for example, 200-500 m, as was the case in respect of the respondents from Poland and Slovakia. It should also be noted that in the literature, for example, in Poland, for years functioned a notion that recreational facilities on the routes should be located at 1000-1500 m (Łonkiewicz and Głuch 1991). However, the recommended distance of positioning points along the routes was based solely on the experience of the authors of the design guidelines, rather than on the results of users' preferences of the forest recreational trails. As shown by the research presented in the article, ideas of designers do not always coincide with the opinion of tourists and vacationing in the woods.

Taking into account the results of research on the functional characteristics of the surface, it can be stated that the respondents have shown great pragmatism in selecting surface most friendly to people with disabilities in wheelchairs. Three most preferred and highest rated types of surfaces in Poland are asphalt, concrete slabs and paving stones in a little part of a forest landscape; they are certainly pavements that are so ecological and, besides, in the structure of the network of forest roads do not occur as often as ground roads. Amongst the respondent from the Czech Republic and Slovakia, paving of cobblestones or concrete slabs are seen as less suitable for wheelchair access than those from Poland. It seems that this is related to the fact that in the Czech Republic and Slovakia, surfaces made of concrete slabs and granite are quite popular in the forests, in contrast to the Polish conditions (Loučková and Fialová 2010). Granite stones is characterised by an uneven surface; therefore, it can be a big obstacle for wheelchair users. On the other hand, in the case of concrete slabs, difficulty is represented generally in the joining of the consecutive panels (Jakubisová 2013). Surprisingly, the authors of the research found that the fact that the vast majority of respondents from Poland, the Czech Republic and Slovakia have acknowledged the usefulness of the hopper surfaces made of wood is unsuitable (i.e. the wooden sidewalks). This is all the more puzzling that quite a lot of routes prepared for people with disabilities in the woods is made of wood (e.g. in Poland: 'Royal Springs' in Kozienice Forest District and 'The Royal Oak Route and Grand Dukes of Lithuania' in the Białowieża Forest District). As rightly observed (Kotásková 2010), wood surface in the rain becomes slippery and so unfriendly for people in wheelchairs. Thus, once again it proves that the views of designers and initiators of the emerging infrastructure of recreation in forests designated for people with disabilities in wheelchairs are not always consistent with their preferences, needs and expectations.

\section{SUMMARY}

The study found a number of significant differences in the views of people with disabilities surveyed in Poland, the Czech Republic and Slovakia. A proper understanding of the differences in the preferences of the respondents require further research to establish the relationship between their views on forest trails for recreation and features such as the period of use of wheelchairs, 
their types (stable, electric initially, the three-wheel, handcycle and others) and a group of disability (paraplegia, tertraplegia and others). Zoning traffic intensity of recreational forests and the creation of modern rules of access to and development of recreational forest must take into account the needs and expectations of disabled users of the area. This issue is still little understood. As a result, the current guidelines for recreational trails in the woods, in both Poland and neighbouring countries, hardly contribute to the formation of routes friendly to people with disabilities in wheelchairs.

\section{Acknowledgement}

The article was created with the support of the project Trails for disabled people in the V4 countries (International Visegrad Fund's Small Grant No. 11510242).

\section{References}

CSO Statistical Yearbook 2014.

Czech Republic Statistical Office in 2014.

Jakubis M., Jakubisová M. 2010. The proposal of revitalization, recreational and educational utilization of Komorovske ponds in cadastral area Banska Stavnica. In: Public recreation and landscape protection - with man hand in hand (ed.: J. Fialova). Conference proceeding 01- 03.05.2010, Brno. Mendelova Univerzita v Brně, Czech Republic, 92-95.

Jakubisová M. 2013. Touristic and educational polygon for visitors with disabilities in Protected Site Borova Hora Arboretum of the Technical University in Zvolen. Journal of Landscape Management, 4 (1), 60-66.

Junek J., Fialová J. 2012. Presentation and disclosure of protected areas for disabled people - Without barriers in Pieniny and TANAP. In: Public recreation and landscape protection - hand in hand (ed.: J. Fialová). Mendelova Univerzita v Brně, Czech Republic, 63-68.

Kotásková P. 2010. The solution of problematic points of timber buildings reconstruction. In: Colloquium of landscape management (ed.: M. Kravka). Mendelova Univezita v Brne, Czech Republic, 70-78.

Łobożewicz T. 2000. Tourism and recreation of people with disabilities. Higher School of Economics, Warsaw, Poland.

Łonkiewicz B., Głuch G. 1991. Guidelines recreational forest management. Forest Research Institute, Warsaw, Poland.

Loučková K., Fialová J. 2010. The accessing of the landscape and recreational activities for seniors and disabled people. In: Recreation and nature protection (ed.: J. Fialová). Mendelova Univerzita v Brně, Czech Republic, 194-197.

Navratil J., Knotek J., Picha K., Fialová J. 2015. The protected areas: are they still in the "pleasure periphery" or they are destinations for sustainable tourism activities? European Journal of Tourism Research, $11,57-72$.

Płocka J. 2002. Selected problems of tourism development. CKU, Toruń, Poland.

Statistical Office of the Slovak Republic. 2014

Weiss M. 1979. Possibility of hiking for people with disabilities In: Social aspects of tourism. IT, Warsaw, Poland, 116-121.

Wolski J. 1979. Prophylactic, therapeutic and rehabilitative functions of tourism. In: Social needs and the development of tourism in Poland. GKTiLT, Warsaw, Poland, 34-48.

Woźnicka M. 2006. Engineering development of urban forests Warsaw - conditions ergonomic elements of tourist infrastructure, $\mathrm{PhD}$ thesis, University of Life Sciences, Warsaw, Poland.

Woźnicka M. 2007. Assessment of adapting urban forests Warsaw to the needs of people in wheelchairs. In: Urban greenery - the natural wealth of the city: the forests in the cities of the European Union - the principles of management and protection (eds.: E. Oleksiejuk, A. Jankowska), PZIiTS Toruń, Poland, 133-140.

Woźnicka M. 2009. Opportunities to provide a forest for recreational needs of the disabled. In: Recreation Physical education and health promotion (eds.: Z. Kubińska, D. Nałęcka). T.1, PWSZ them. Pope John Paul II, Biala Podlaska, Poland, 27-35. 